\title{
Novel phenolic resin hollow microspheres: Flame retardancy and toxicity reduction in thermoplastic polyurethane elastomer
}

\author{
C. M. Jiao, Y. L. Zhang, H. X. Dong, W. J. Chen, W. Liu, S. X. Li, X. L. Chen* \\ College of Environment and Safety Engineering, Qingdao University of Science and Technology, Qingdao, 266042 \\ Shandong, P R China
}

Received 12 February 2021; accepted in revised form 10 April 2021

\begin{abstract}
In this paper, phenolic resin hollow microspheres (PHM) were prepared using in-situ polymerization and used as flame-retardants for TPU. The structure and composition of PHM were characterized by Scanning Electron Microscope (SEM). The potential of PHM as flame retardant was verified by thermogravimetric analysis (TG). Then, the flame retardancy and toxicity reduction of PHM in TPU/PHM composites were verified by cone calorimeter test (CCT) and Thermogravimetric Analysis-infrared Spectrometry (TG-IR). It has been found that comparing TPU/PHM-4 sample containing $4.0 \mathrm{wt} \% \mathrm{PHM}$ with pure TPU, the peak heat release rate (pHRR) was reduced by $61.6 \%$, the total smoke release (TSR) by $23.2 \%$, and the CO production by $86.2 \%$, respectively. The SEM, Laser Raman Spectroscopy Test (LRS), and other tests were carried out to test the char residues after CCT, and the mechanism of PHM in the process of flame retardant TPU was reasonably deduced. In a word, PHM is very effective as a flame retardant of TPU.
\end{abstract}

Keywords: thermal properties, thermoplastic polyurethane elastomers, flame retardancy, toxicity reduction

\section{Introduction}

As an essential material in industrial production and people's daily life, TPU is a kind of green and environmentally friendly polymer material with high mechanical strength and good processing performance [1-3]. However, TPU is very easy to burn when exposed to a fire environment, producing a lot of heat and generating a lot of smoke and toxic gas at the same time, causing severe damage to human life and the environment [4-12]. Therefore, to develop fire safety of TPU is very necessary. It has been found an excellent way to enhance the fireproof ability of TPU is using flame-retardants. Flame-retardants can be divided into halogen and halogen-free flame-retardants. Although flame retardants containing halogen have been widely used in TPU, it contrary to the view of green chemistry due to a great deal of smoke and toxic gas that threatens people's lives [13]. Accordingly, it is quite important to find a halogen-free flame retardant that conforms to the concept of green chemistry. In addition, a lot of halogen-free flame retardants had made great contributions to retard flame spread, smoke suppression, poison reduction, and environmental protection [14-16].

In recent years, the rise of 3D nano flame retardant materials, hollow materials have gradually aroused extensive research interest. Among them, the hollow sphere is famous for a large specific surface area, lightweight, good compatibility, and thermal insulation [17-22]. When it is used to the polymer as a flame retardant, it can induce carbonization to form a heat-insulating layer and obtain good flame retardancy [7, 23-25]. Hollow mesoporous silica (HMS) microspheres were prepared by Wang et al. [26]. 
Because HMS microspheres had a hollow structure, they had a high removal ability for volatile aromatic compounds, and the effect of inhibiting toxicity was obvious. Qiu et al. [27] prepared a three-dimensional nanostructure, which connected the hollow carbon nanospheres with $\mathrm{Co}_{2} \mathrm{P}$ and graphene sheets, and introduced them into the epoxy resin. The results showed that the three-dimensional nanostructure could effectively improve the flame retardancy and toxicity elimination ability and raise a protective char residue layer with high graphitization in the burning process of the epoxy resin.

Because phenolic resin (PR) can be widely used in all walks of life as a fire safety agent of other polymer materials [28-30], and it has a low price, good mechanical properties and heat resistance, flame retardancy, less smoke and high char residue rate after combustion [31-33]. This paper envisaged whether the preparation of phenolic resin hollow microspheres could be used in flame retardant TPU. After consulting a large several pieces of literature, it was found that the phenolic resin hollow microspheres with high performance were prepared by Liu et al. [34]. The product had good thermal stability. Guo et al. [35] introduced phenolic resin hollow microspheres into oligo aryl epoxy resin. The results showed that the continuous dense porous expanded char residue layer was raised in the combustion process, and the flame retardancy was good. Although phenolic resin hollow microspheres have many excellent properties, there is a lack of research on its utilization in flame retardant TPU.

Here, phenolic resin hollow microspheres were prepared and applied as flame retardant for TPU in different proportion. Firstly, the structure and morphology of PHM were characterized using LRS, TG, and SEM. Secondly, the flame retardancy and thermal degradation of TPU composite were investigated by Microscale Combustion Calorimeter Test (MCC), CCT, and Thermogravimetric Analysis-infrared Spectrometry (TG-IR), respectively. In addition, the structure of the char residue layer after CCT was analyzed by SEM and LRS, respectively.

\section{Experimental section \\ 2.1. Materials}

TPU (9380A) was from Bayer, Germany. $\mathrm{NaOH}$, $\mathrm{HCl}$, phenol, and formaldehyde were from Rhawn Co., Ltd (China). Ethyl orthosilicate (TEOS) was from
BASF Chemical Trade Co., Ltd (China). Polyacrylic acid (PAA) was from Kemio Chemical Reagent Co., Ltd (China).

\subsection{Synthesis of PHM}

Aqueous formaldehyde $(37 \mathrm{wt} \%, 12.5 \mathrm{ml})$ and phenol $(9.5 \mathrm{~g})$ were added into the beaker, and $\mathrm{NaOH}$ $(0.1 \mathrm{~mol} / \mathrm{l})$ was added dropwise into this beaker while stirring ( $800 \mathrm{rpm})$ to adjust $\mathrm{pH}$ to 10 . Then the reaction temperature was kept at about $70^{\circ} \mathrm{C}$ for 3 hours. After cooling to $25^{\circ} \mathrm{C}$ and neutralizing with $\mathrm{HCI}$ to $\mathrm{pH}$ about 7, PR was obtained.

$150 \mathrm{ml}$ water, $30 \mathrm{ml}$ TEOS, and $60 \mathrm{ml}$ PAA were added into another beaker to obtain a mixed solution, which was stirred at the rate of $800 \mathrm{rpm}$ for $20 \mathrm{~min}$. Then PR was added dropwise into the above, mixed solution, and $\mathrm{HCl}$ was added dropwise to regulate the $\mathrm{pH}$ to 1 of the reaction system. Afterward, the mixture was heated to $90^{\circ} \mathrm{C}$ and stirred for $3 \mathrm{~h}$. Then, orange microparticles were obtained, filtered, and separated; the product was heated to $170^{\circ} \mathrm{C}$ to remove TEOS. And microspheres were cured at $200^{\circ} \mathrm{C}$ for $3 \mathrm{~h}$ to further form 3D networks. The preparation route of PHM was shown in Figure 1.

\subsection{Preparation of TPU/PHM composites}

TPU composites with different amounts of PHM were prepared on a two-roll mill at $180^{\circ} \mathrm{C}$ with a rotor speed of $30 \mathrm{rpm}$ for $15 \mathrm{~min}$. For example, TPU blends with $4.0 \mathrm{wt} \%$ PHM was denoted as TPU/P-4. Then TPU/P-4 sample was hot-pressed at $180^{\circ} \mathrm{C}$ for $15 \mathrm{~min}$ (10 MPa) and then cool naturally to room temperature. After forming, cut the appropriate size of the sample for analysis. In addition, in order to prepare TPU/P-1 (1.0 wt \%), TPU/P-2 (2.0 wt \%), and TPU/P$3(3.0 \mathrm{wt} \%)$ composites, similar processes were used except for the different proportion of additives.

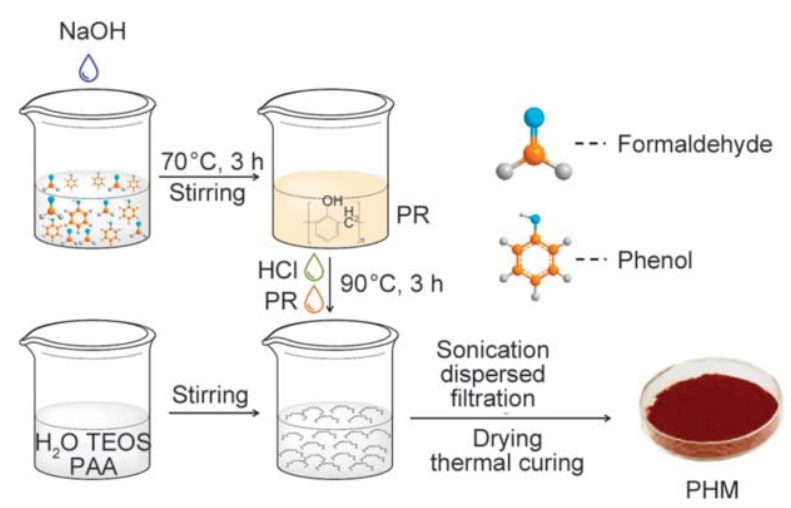

Figure 1. The preparation of PHM. 


\subsection{Measurements}

\subsubsection{Thermogravimetric analysis (TGA)}

Each sample was analyzed by thermogravimetry (TG) using a DT-50 (French Setaram) instrument. Under the $\mathrm{N}_{2}$ and air atmosphere (the flow rate is $20 \mathrm{ml} / \mathrm{min}$ ), about $10.0 \mathrm{mg}$ of samples within the crucible (alumina) were heated from 35 to $720^{\circ} \mathrm{C}$ $(20 \mathrm{~K} / \mathrm{min})$.

\subsubsection{Fourier transform infrared measurement (FT-IR)}

FT-IR spectra of samples were measured by an IR Affinity-1 FTIR spectrometer (Japan) with $4 \mathrm{~cm}^{-1}$ resolutions over 32 scans using $\mathrm{KBr}$ disk in the range of $4000-500 \mathrm{~cm}^{-1}$.

\subsubsection{Cone calorimeter test (CCT)}

Cone calorimeter (Stanton Redcroft, London, UK) tests were used to detect the burning behavior of the samples. Every specimen was in the size of $100 \times 100 \times 3 \mathrm{~mm}^{3}$, then was wrapped in aluminum foil and exposed to a heat flux of $35 \mathrm{~kW} / \mathrm{m}^{2}$.

\subsubsection{Scanning electron microscope (SEM)}

SEM (EVO MA15, Zeiss) combined with energy dispersive X-ray spectrometry (EDX) was used to observe the morphological features. Before the test, the sample surface was evenly sputtered with a gold plating layer.

\subsubsection{Thermogravimetric analysis-infrared spectrometry (TG-IR)}

The pyrolysis gas of TG entered the IR Affinity-1 FTIR spectrometer (Japan) through the connecting tube $\left(220^{\circ} \mathrm{C}\right)$ for testing at a heating rate of $20^{\circ} \mathrm{C} /$ min under $\mathrm{N}_{2}$ atmosphere. The temperature ranged from 35 to $750^{\circ} \mathrm{C}$.

\subsubsection{Laser Raman spectroscopy test (LRS)}

The integration time of the LRS was $200 \mathrm{~s}$, and the scanning range was $5000-40 \mathrm{~cm}^{-1}$. The test sample was from the surface of the char residue layer after CCT. In addition, this test was measured at an ambient temperature of Horiba Scientific Lab Ram HR Evolution.

\subsubsection{Microscale combustion calorimeter test (MCC)}

The combustion behavior of the samples was also investigated by a microscale combustion calorimeter (MCC-2, Govemark Ltd, McHenry, Illinois). Every test needs about $5.0 \mathrm{mg}$ of samples which were placed in a crucible $\left(\mathrm{Al}_{2} \mathrm{O}_{3}\right)$ and heated from 75 to $750{ }^{\circ} \mathrm{C}(1 \mathrm{~K} / \mathrm{s})$.

\section{Result and discussion}

\subsection{Characterization of PHM}

Figure 2a shows the thermogravimetric curves under $\mathrm{N}_{2}$ and air atmosphere, respectively. In Figure 2a,
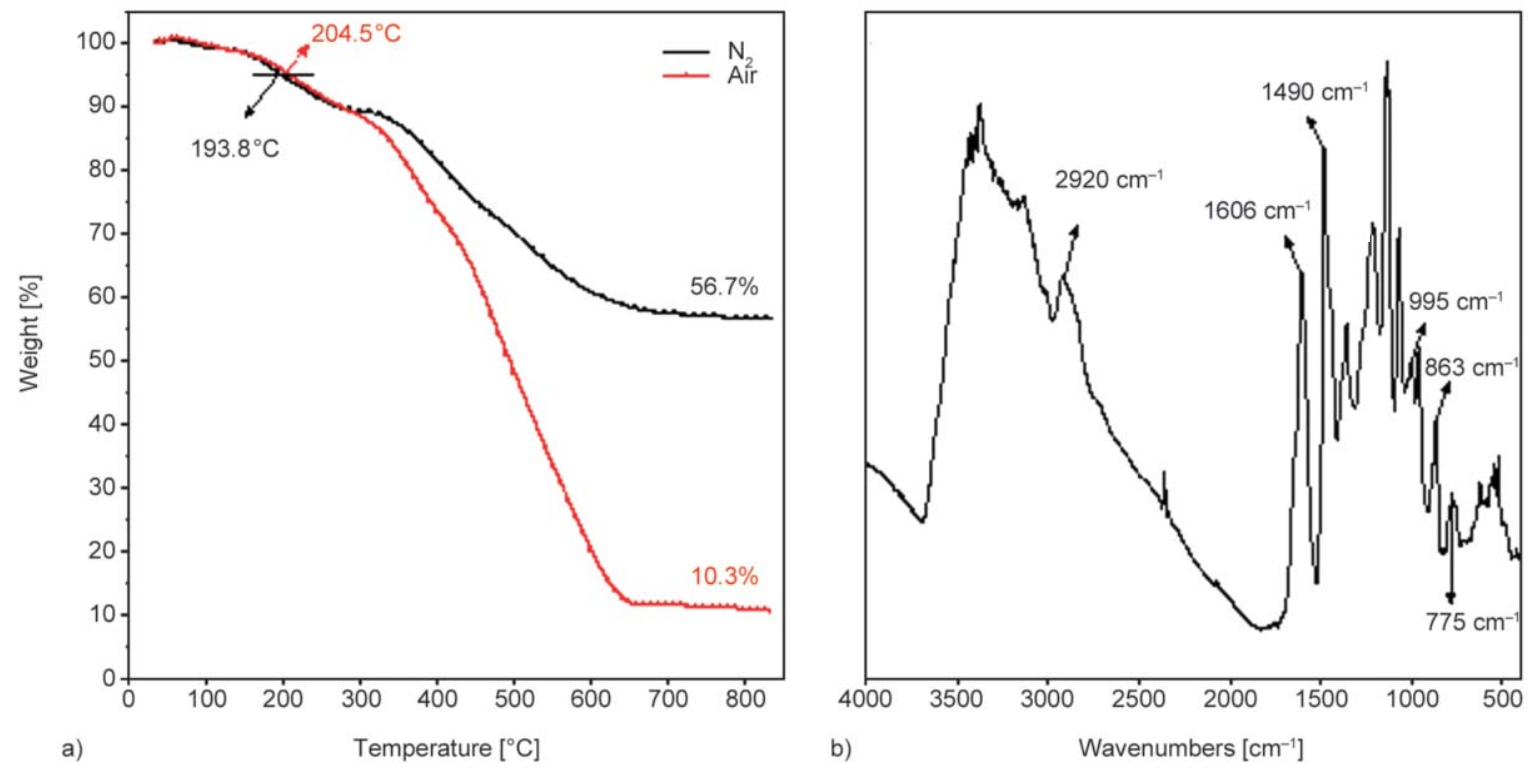

Figure 2. TGA under $\mathrm{N}_{2}$ and air atmosphere (a) and FT-IR spectra (b) of PHM. 
PHM had four obvious weight-loss peaks at about $98,191,404$ and $523^{\circ} \mathrm{C}$, respectively, in the atmosphere of $\mathrm{N}_{2}$ and air. The first peak was attributed to the volatilization of adsorbed water. The second peak was for the degradation of $-\mathrm{CH}_{2}$. At $404{ }^{\circ} \mathrm{C}$, the crosslinking network was broken. And after $500^{\circ} \mathrm{C}$, $\mathrm{C}-\mathrm{OH}$ in phenol was broken [36]. It is worth noting that under both atmospheric conditions, the final residual masses were $56.7 \%\left(\mathrm{~N}_{2}\right)$ and $10.3 \%$ (air), respectively, which proved that PHM had good thermal stability at high temperature [34, 35]. Figure $2 b$ was the IR spectrum of PHM. It could be seen that there were no free phenols, strong methylene stretching vibration at $2920 \mathrm{~cm}^{-1}$, hydrocarbon stretching vibration at $1490 \mathrm{~cm}^{-1}$, characteristic peak of benzene ring at $1606 \mathrm{~cm}^{-1}$, and ortho para characteristic peaks substituted by benzene ring at 775 and $863 \mathrm{~cm}^{-1}$, respectively, indicating that there was curing reaction in the reaction process, forming a three-dimensional structure, and benzyl hydroxyl stretching vibration at $995 \mathrm{~cm}^{-1}$, with relatively high strength. The results showed that the curing reaction of PHM was relatively complete [26,34].

Figure 3 was the SEM characterization of PHM. Clearly, in Figure 3a, most of PHM particles were within $100 \mu \mathrm{m}$, and the wall thickness of PHM was within about 5 um, with a good closed-cell structure. Because the PHM had a hollow closed-cell structure, its thermal conductivity was small [37-39], which may be helpful to improve the heat insulation ability and flame retardancy of the TPU composites.

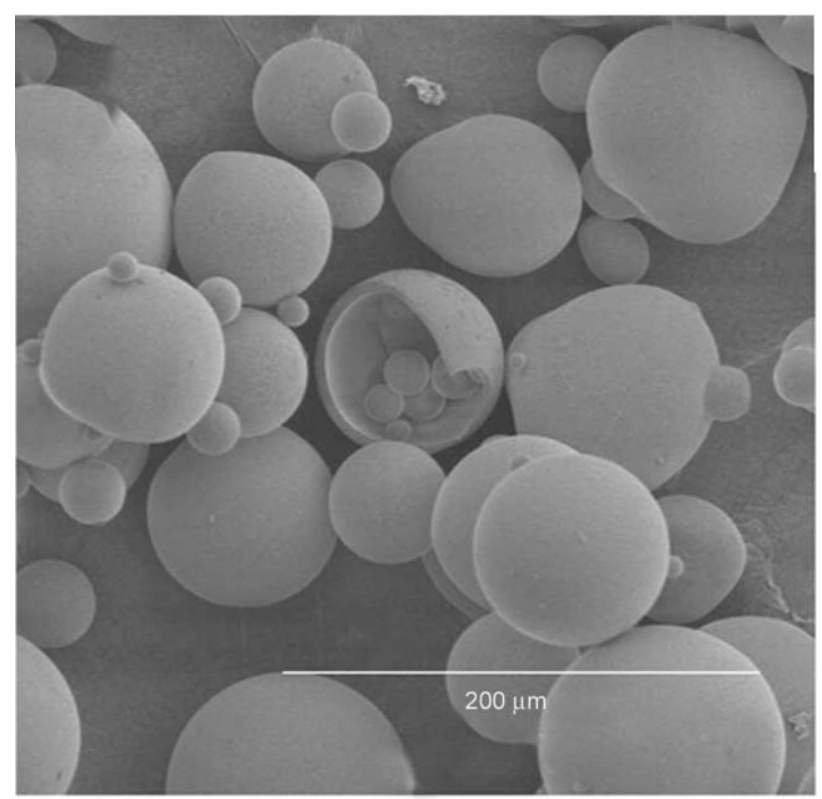

a)

Figure 3. SEM (a) and EDX (b) images of PHM.
Figure $3 \mathrm{~b}$ was the EDX characterization of PHM, and it could be seen that there were a large number of $\mathrm{C}$ elements on the surface of PHM, which may be helpful for the formation of the char residue layer. In addition, there was a small amount of $\mathrm{O}$ and $\mathrm{Na}$ elements on the surface of PHM, but no Si element. It was proved that $\mathrm{Na}$ was not completely removed, while TEOS was successfully removed during the preparation of PHM.

\subsection{Combustion behaviour of TPU/PHM composites}

For flame retardant materials, the heat, smoke, and toxic parameters are very important. Thus a series of data could be obtained by CCT to assess the flame retardancy of testing materials, such as time to ignition (TTI), heat release rate (HRR), total heat release (THR), total smoke release (TSR), smoke production rate (SPR), $\mathrm{CO}_{2} / \mathrm{CO}$ generation and so on $[40$ 42]. The relevant combustion parameters from CCT were given in Table 1.

Figure 4 was the curves of SPR, TSR, and CO of TPU composites. In Figure 4a, there had been an obvious double peak phenomenon in the SPR curve. Moreover, the SPR curve of pure TPU reached the first peak $\left(0.032 \mathrm{~m}^{2} / \mathrm{s}\right)$ at $71 \mathrm{~s}$. After $200 \mathrm{~s}$, with the damage of the char residue layer, SPR was gradually raised. At $221 \mathrm{~s}$, SPR reached the highest peak value of $0.107 \mathrm{~m}^{2} / \mathrm{s}$. Obviously, the peak of SPR for the samples with PHM was evidently lower than the peak of SPR of TPU. In addition, with the increase of

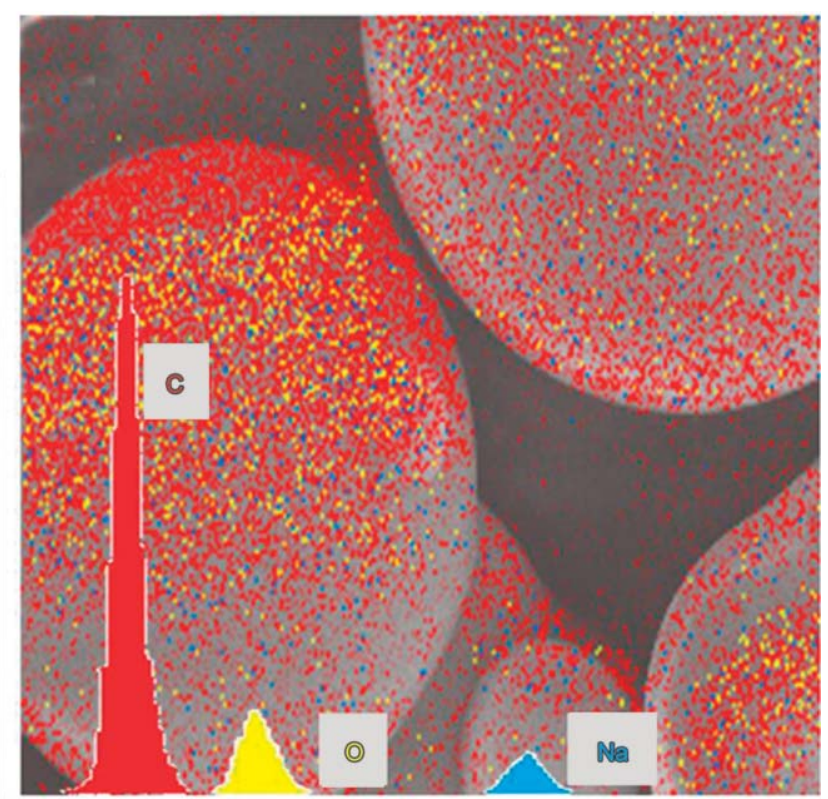

b) 
Table 1. The relevant combustion parameters from cone calorimeter.

\begin{tabular}{|c|c|c|c|c|c|c|c|c|}
\hline Sample & $\begin{array}{c}\text { pHRR } \\
{\left[\mathbf{k W} \cdot \mathbf{m}^{-2}\right]}\end{array}$ & $\begin{array}{c}\text { THR } \\
{\left[\mathbf{M J} \cdot \mathbf{m}^{-2}\right]}\end{array}$ & $\begin{array}{c}\text { TSR } \\
{\left[\mathbf{m}^{2} \cdot \mathbf{m}^{-2}\right]}\end{array}$ & $\begin{array}{c}\text { pSPR } \\
{\left[\mathbf{m}^{2} \cdot \mathbf{s}^{-1}\right]}\end{array}$ & $\begin{array}{c}\text { TTI } \\
{[\mathrm{s}]}\end{array}$ & $\begin{array}{c}\mathbf{S F} \\
{\left[\mathbf{M W} \cdot \mathbf{m}^{-2}\right]}\end{array}$ & $\begin{array}{c}\mathrm{CO} \\
{\left[\mathrm{g} \cdot \mathrm{s}^{-1}\right]}\end{array}$ & $\begin{array}{c}\mathrm{CO}_{2} \\
{\left[\mathrm{~g} \cdot \mathrm{s}^{-1}\right]}\end{array}$ \\
\hline TPU & 1423.8 & 132.8 & 1524.3 & 0.107 & 46 & 2167.0 & 0.029 & 0.912 \\
\hline TPU/P-1 & 599.5 & 146.6 & 1505.2 & 0.065 & 62 & 907.9 & 0.005 & 0.388 \\
\hline TPU/P-2 & 622.4 & 133.9 & 1251.8 & 0.048 & 53 & 778.5 & 0.004 & 0.381 \\
\hline TPU/P-3 & 538.4 & 126.3 & 1309.8 & 0.062 & 56 & 705.3 & 0.006 & 0.347 \\
\hline TPU/P-4 & 547.4 & 123.1 & 1170.9 & 0.045 & 48 & 640.8 & 0.004 & 0.332 \\
\hline
\end{tabular}
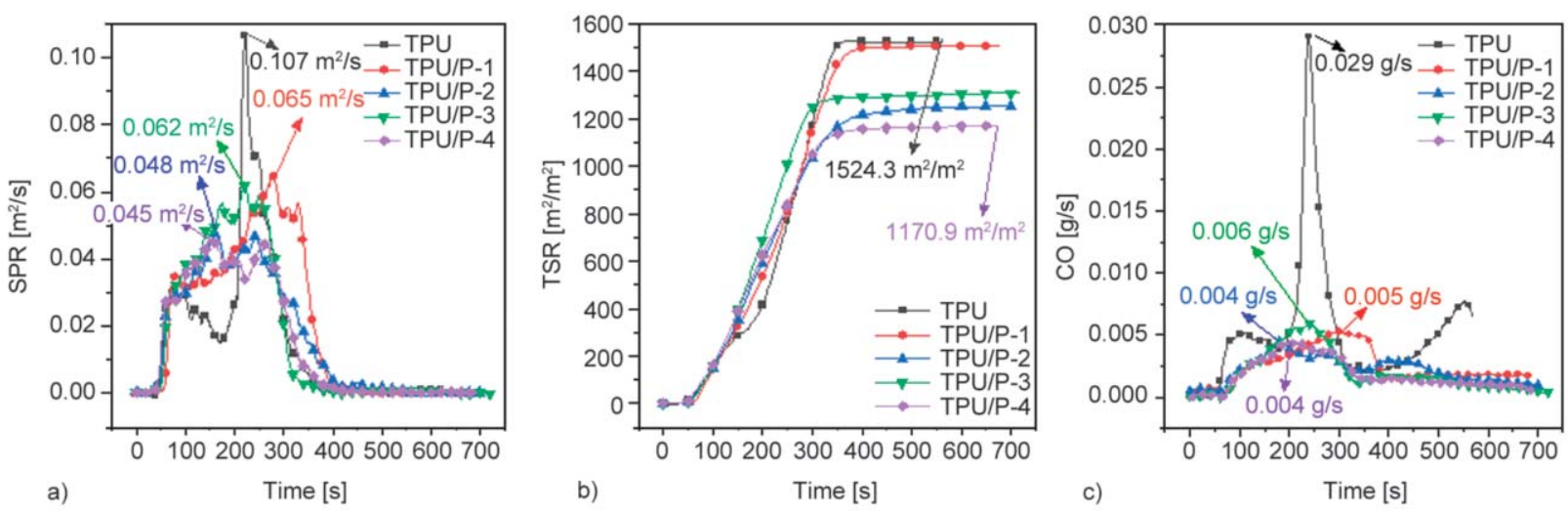

Figure 4. SPR (a); TSR (b) and CO (c) curves of TPU composites.

PHM, the double peak phenomenon disappeared gradually, and the combustion process of the samples with PHM tended to moderate. When the addition of PHM was $4.0 \mathrm{wt} \%$ (TPU/P-4), the peak SPR value of the sample was $0.045 \mathrm{~m}^{2} / \mathrm{s}$, which was $57.9 \%$ lower than that of pure TPU. This fully proved that PHM could effectively suppress smoke [7]. From the TSR curve (Figure 4b), it could also be seen that the addition of PHM could effectively suppress smoke. After about $310 \mathrm{~s}$, the difference between TPU and TPU/PHM samples was extremely stark. At the end of the experiment, the TSR of TPU, TPU/P-1, TPU/P-2, TPU/P-3, and TPU/P-4 were 1524.3, $1505.2,1251.8,1309.8$, and $1170.9 \mathrm{~m}^{2} / \mathrm{m}^{2}$, respectively. The TSR value of the TPU/P-4 sample was $23.2 \%$ less than that of TPU, which meant that the presence of a small amount of PHM could reduce the smoke production of the TPU composite significantly. The results showed that PHM had an obvious smoke suppression effect. Because PHM changed the viscosity of the melt and the structure of the char residue layer during the combustion process of TPU composites [23]. The toxic gas and greenhouse gas generated during the burning process of materials could damage the environment, even people, so it is very important to study the $\mathrm{CO}$ and $\mathrm{CO}_{2}$ given off in the combustion process $[7,9]$. Figure $4 \mathrm{c}$ was the $\mathrm{CO}$ curve, from which it can be seen that the samples with $\mathrm{PHM}$ could effectively reduce the production of $\mathrm{CO}$.
The CO production of pure TPU was $0.029 \mathrm{~g} / \mathrm{s}$, and the CO production of TPU/P-1, TPU/P-2, TPU/P-3 and TPU/P-4 were $0.005,0.004,0.006$, and $0.004 \mathrm{~g} / \mathrm{s}$, respectively. It was undeniable that PHM could effectively inhibit the release of $\mathrm{CO}$. In addition, there was no obvious double peak phenomenon in the composite with PHM. It proved that PHM could improve the quality of the char residue layer, which could avoid $\mathrm{CO}$ entering the combustible area [43]. In Table 1, the $\mathrm{CO}_{2}$ production of TPU, TPU/P-1, TPU/P-2, TPU/P-3 and TPU/P-4 were 0.912, 0.388, $0.381,0.347$ and $0.332 \mathrm{~g} / \mathrm{s}$, respectively. The $\mathrm{CO}_{2}$ production of the TPU/P-4 sample was $63.6 \%$ lower than that of TPU. In addition, with the addition of PHM, the combustion process became moderate. Therefore, it could be considered that TPU/PHM could form a dense protective char residue layer and prevented the gas exchange between the substrate material and the environment $[44,45]$. SF value was obtained by the product of pHRR and TSR [46]. It can be seen in Table 1, at the end of the experiment, the SF curves of TPU, TPU/P-1, TPU/P-2, TPU/P-3, and TPU/P-4 were 2167.0, 907.9, 778.5, 705.3, and $640.8 \mathrm{MW} / \mathrm{m}^{2}$, respectively. It can be concluded that PHM could reduce the smoke generated during the combustion of TPU, and reduce the harm of combustion.

Figure 5 showed the curves of HRR and THR. Figure $5 \mathrm{a}$ was the HRR curve. The pHRR value of pure 


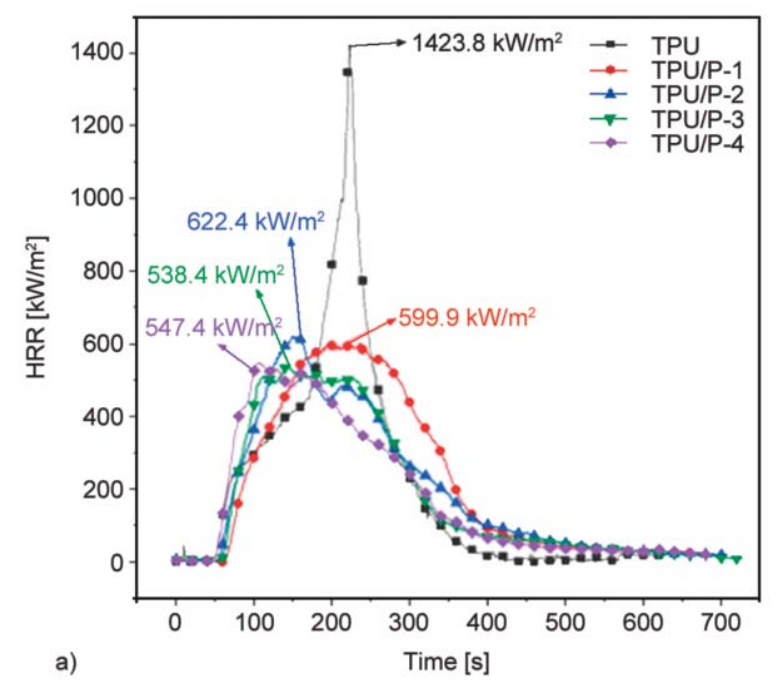

Figure 5. HRR (a) and THR (b) curves of TPU composites.

TPU was $1423.8 \mathrm{~kW} / \mathrm{m}^{2}(222 \mathrm{~s})$. With the addition of PHM, the pHRR value decreased, corresponding to the peak value of TPU/P-1, TPU/P-2, TPU/P-3 and TPU/P-4 were $599.5 \mathrm{~kW} / \mathrm{m}^{2} \quad(237 \mathrm{~s})$, $622.4 \mathrm{~kW} / \mathrm{m}^{2}(149 \mathrm{~s}), 538.4 \mathrm{~kW} / \mathrm{m}^{2}(142 \mathrm{~s})$ and $547.4 \mathrm{~kW} / \mathrm{m}^{2}(103 \mathrm{~s})$, respectively. In particular, compared with pure TPU, the pHRR of TPU/P-3 decreased by $62.2 \%$. In addition, the samples with PHM also had a plateau region. It could be considered that PHM could make the combustion moderate; maybe in the process of combustion, PHM could migrate quickly onto the surface of the samples, promote the formation of dense char residue layer, and effectively prevent combustible gas from entering the flame zone [23]. The THR curve was shown in Figure $5 \mathrm{~b}$. At the end of the experiment, the THR value of pure TPU was $132.8 \mathrm{~kJ} / \mathrm{m}^{2}$, the THR value of the TPU/P-4 sample was $123.1 \mathrm{~kJ} / \mathrm{m}^{2}$, which was $7.3 \%$ lower than that of TPU, and the fire spread degree of TPU/P-4 sample was the slowest among all samples [47]. It can be concluded that PHM could change the viscosity of TPU at the initial stage of the test, thus migrating to the surface of TPU and forming a good insulating hollow layer, thus prolonging the TTI. In the meantime, with the up migration of PHM, the release of combustible gas and heat was reduced [48].

\subsection{Analysis of char residue layer after CCT}

Figure 6 shows the pictures of the char residue layer after CCT. The char residue layer of TPU (Figure 6a) was relatively loose evidently, and the char residue layer of TPU/P-4 (Figure 6b) was relatively dense. Furtherly, the SEM results showed that there were

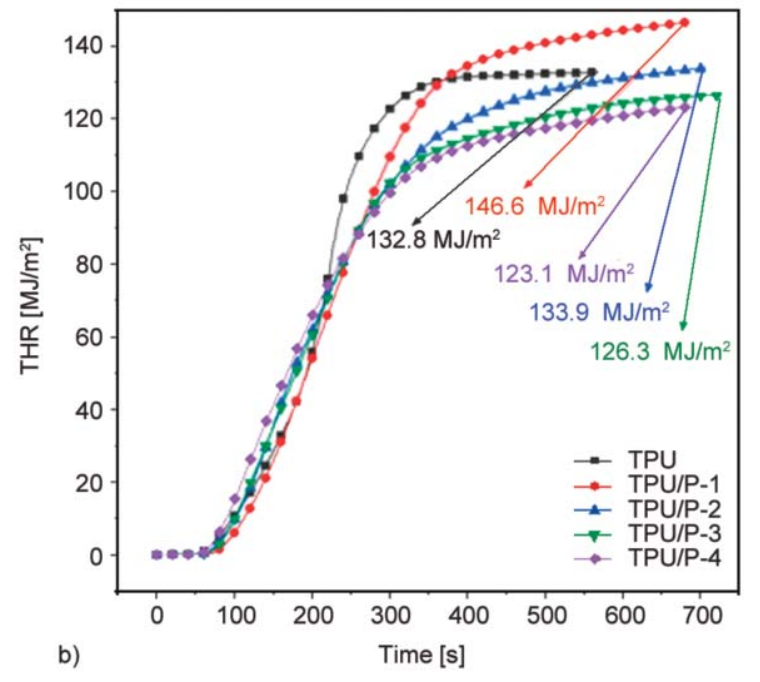

obvious cracks on the surface of the char residue layer of pure TPU in Figure 6a, which could not play a protective role. This indicated that the char residue layer of TPU was brittle and easy to crack [44, 4951]. In Figure $6 b$, the surface of the char residue layer of TPU/P-4 was compact, and there were no cracks and holes. The enlarged pictures showed that the surface of the char residue layer of TPU (Figure 6c) was smooth. However, TPU/P-4 (Figure 6d) was covered with spherical protrusions, which confirm that PHM migrated onto the surface of TPU during combustion and could form a hollow surface structure, reducing the thermal conductivity of the char residue layer and effectively protecting the underlying material during combustion. In addition, in Figure $6 \mathrm{c}$ and $6 \mathrm{~d}$, the content of $\mathrm{C}$ and $\mathrm{O}$ on the surface of the char residue layer from pure TPU was most significantly lower than that from the TPU/P-4 sample. Moreover, the surface of the TPU/P-4 char residue layer contained $\mathrm{Na}$ element that changed into needle-like $\mathrm{Na}_{2} \mathrm{O}$. It was confirmed that PHM successfully migrated onto the surface of TPU composites in the combustion process [44].

LRS was taken to confirm that the protection of the outer surface of the char residue layer of TPU/P-4 after CCT. [50]. In Figure 7, there were two strong peaks at 1366 (band D) and $1591 \mathrm{~cm}^{-1}$ (band G). The smaller the ratio of integral strength $\left(I_{\mathrm{D}} / I_{\mathrm{G}}\right)$, the better the graphitization degree of the char residue layer, and the better the protection of underlying materials [27]. $I_{\mathrm{D}} / I_{\mathrm{G}}$ of char residue layer of pure TPU was 3.85 , and $I_{\mathrm{D}} / I_{\mathrm{G}}$ of char residue layer of TPU/P-4 sample was 3.24. This meant that PHM could form a char residue layer with high quality. Therefore, the 


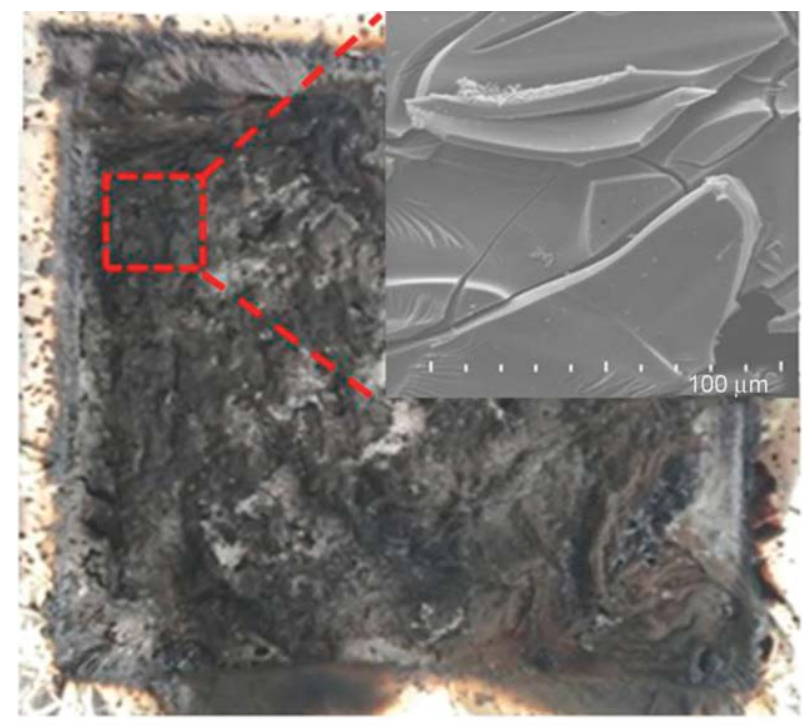

a)

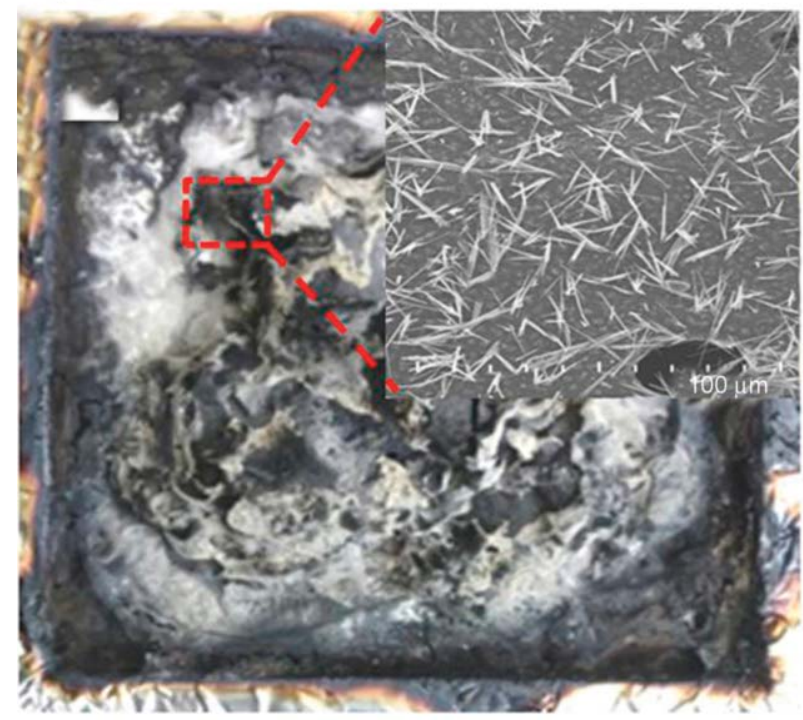

b)

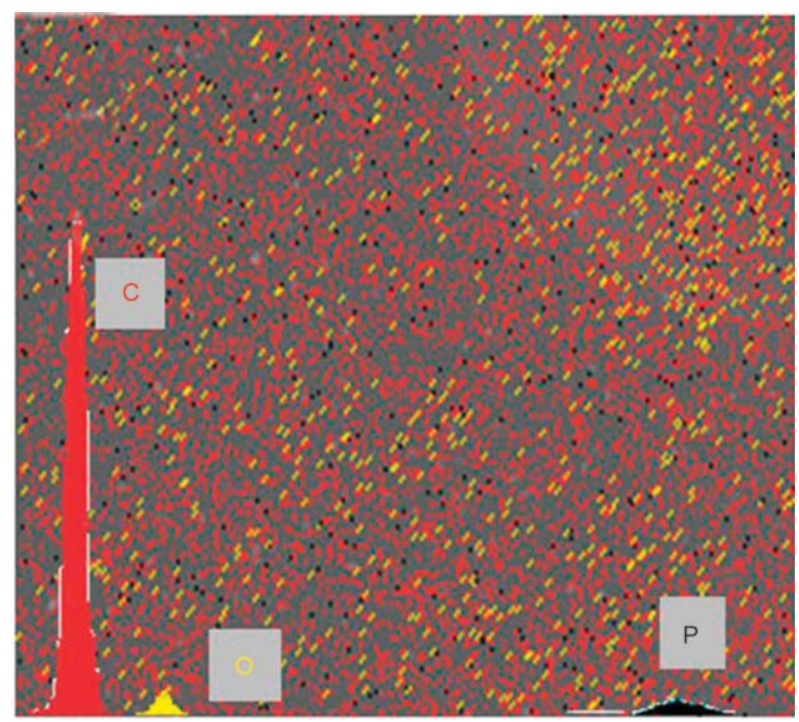

c)

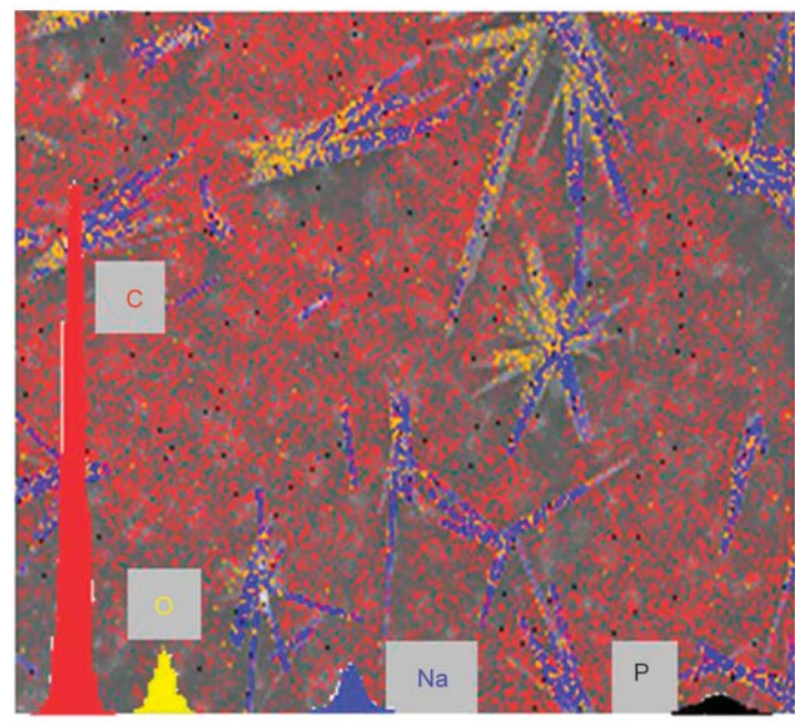

d)

Figure 6. Digital photos and SEM images of char residue layer of TPU (a) and TPU/P-4 (b), EDX scanned photos of char residue layer of TPU (c) and TPU/P-4 (d).

outer surface of the char residue layer of TPU/P-4 could protect the underlying material well.

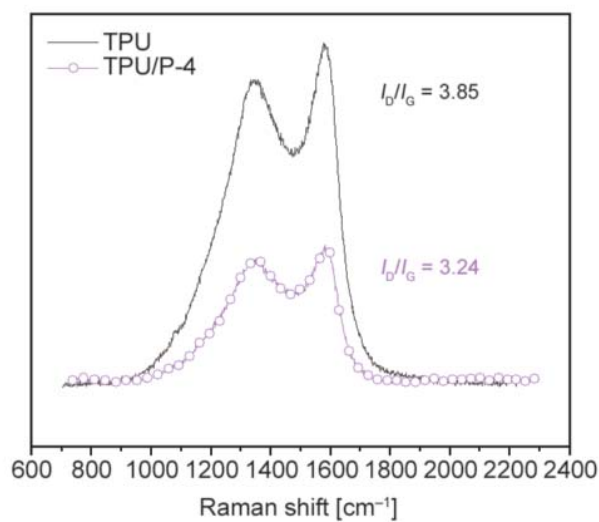

Figure 7. Raman spectra of char residue layer of TPU and TPU/P-4.

\subsection{Thermal decomposition of pure TPU and TPU/P-4}

Before the combustion of polymer materials, the first step is the decomposition of polymer materials to produce combustible gas. Therefore, the thermal decomposition behavior of polymer materials is a matter of cardinal significance for the flame retardancy of polymer materials. TG-IR test was always used to explain the thermal decomposition behaviors of flame retardant polymer materials $[41,52]$.

Figure 8 shows the $\mathrm{TG}$ results in $\mathrm{N}_{2}$ atmosphere. In addition, the relevant data was given in Table 2. In Figure $8 \mathrm{a}$, the $T_{5 \%}$ of pure TPU was about $355.7^{\circ} \mathrm{C}$, and it was completely decomposed at about $600^{\circ} \mathrm{C}$. In addition, the $T_{5 \%}$ of TPU/P-4 sample was about $339.5^{\circ} \mathrm{C}$, which was slightly earlier than that of pure 
TPU. This could be illustrated that PHM could catalyze the decomposition of TPU in the early stage of the experiment to form some volatile compounds into the gas phase. At the same time, there was some residue formed. When the temperature was raised, the formation of the char residue layer took great importance in the early stage and improved the thermal stability of the TPU/P-4 sample at a high temperature. So, the char residue at $720^{\circ} \mathrm{C}$ of TPU/P-4 was significantly more than that of TPU, because the residue of TPU/P-4 is $11.3 \%$, higher than the theoretical value of $8.3 \%(56.7 \% \cdot 0.04+6.3 \% \cdot 0.96)$, which proved that PHM could enhance the formation of high-quality char residue layer of TPU. In Figure 8 b, the dTG peak value of TPU was about $-27.2 \% / \mathrm{min}$ at $419.7^{\circ} \mathrm{C}$, and the peak value of TPU/ P-4 was about $-19.1 \% / \mathrm{min}$ at $410.7^{\circ} \mathrm{C}$, which was significantly lower and earlier than that of pure TPU. It was proved that PHM could promote the decomposition of TPU to form a dense char residue layer at low temperature, strong the structure of the char residue layer, which could play some protective role in the most vigorous stage of fire development [42].

The volatile products from TG were analyzed using infrared spectroscopy. In addition, TG-IR results in $\mathrm{N}_{2}$ atmosphere were given in Figure 9. The spectra

Table 2. Thermogravimetric data of TPU and its composites in $\mathrm{N}_{2}$ atmosphere.

\begin{tabular}{|l|c|c|c|}
\hline Samples & $\begin{array}{c}\boldsymbol{T}_{\mathbf{5} \%} \\
{\left[{ }^{\circ} \mathbf{C}\right]}\end{array}$ & $\begin{array}{c}\boldsymbol{T}_{\max } \\
{\left[{ }^{\circ} \mathbf{C}\right]}\end{array}$ & $\begin{array}{c}\text { Char residue at } \mathbf{7 2 0}^{\circ}{ }^{\circ} \mathbf{C} \\
{[\mathbf{w t} \mathbf{\%}[}\end{array}$ \\
\hline TPU & 355.7 & 419.7 & 6.3 \\
\hline TPU/P-4 & 339.5 & 410.7 & 11.3 \\
\hline
\end{tabular}

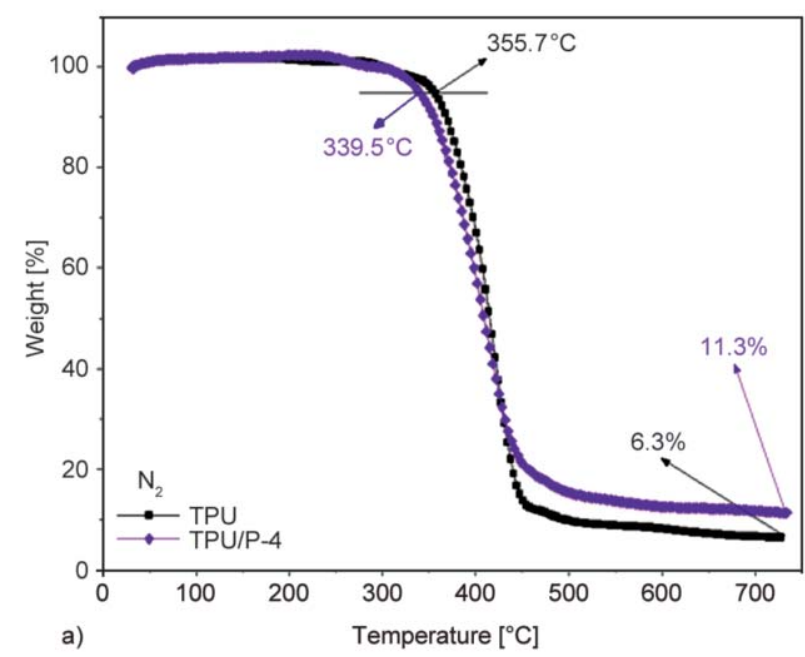

of pure TPU (Figure 9a) and TPU/P-4 (Figure 9b) were similar. For example, $\mathrm{CH}_{3}\left(2967 \mathrm{~cm}^{-1}\right), \mathrm{CH}_{2}$ $\left(2866 \mathrm{~cm}^{-1}\right), \mathrm{CO}_{2}\left(2359 \mathrm{~cm}^{-1}\right), \mathrm{C}=\mathrm{O}\left(1752 \mathrm{~cm}^{-1}\right)$, aromatic compounds ( 1509 and $\left.1461 \mathrm{~cm}^{-1}\right), \mathrm{C}-\mathrm{O}-\mathrm{C}$ $\left(1101 \mathrm{~cm}^{-1}\right)$, all of these peaks appeared in Figure 9a and $b$. In addition, the band at $723 \mathrm{~cm}^{-1}$ could distribute HCN. This showed that the main types of volatile products of TPU would not change with the addition of PHM [50, 53]. However, it was obvious that the gas phase products of TPU/P-4 appeared earlier than that of TPU. For example, HCN from TPU appeared at $280^{\circ} \mathrm{C}$, while that from TPU/P-4 appeared at $220^{\circ} \mathrm{C}$. The aromatic compounds from TPU appeared at $260^{\circ} \mathrm{C}$, which from TPU/P-4 appeared at $240^{\circ} \mathrm{C}$. The $\mathrm{CO}_{2}$ from TPU reached the maximum value at $480^{\circ} \mathrm{C}$, and decreased significantly at $600^{\circ} \mathrm{C}$, while that from TPU/P-4 reached the maximum value at $440{ }^{\circ} \mathrm{C}$, and decreased at $520^{\circ} \mathrm{C}$. This was similar to the test results of CCT. It was proved that PHM could catalyze TPU to decompose in advance, promoted the formation of a high-quality protective char residue layer of TPU, prevented the material exchange between the underlying material and the environment, and had an obvious effect on inhibiting toxicity. $\mathrm{HCN}$, in particular, was a major toxicant in the degradation of TPU. The HCN product from TPU/P-4 reached the maximum value $60^{\circ} \mathrm{C}$ earlier than that from TPU at $420^{\circ} \mathrm{C}$, and TPU/P-4 basically did not release $\mathrm{HCN}$ after $520^{\circ} \mathrm{C}$. The pure TPU released $\mathrm{HCN}$ all the time before the end of the experiment. In other words, combined with SEM photos of the char residue layer, the char residue layer of TPU/P-4 had a strong protective effect and could effectively inhibit the release of toxic gas.

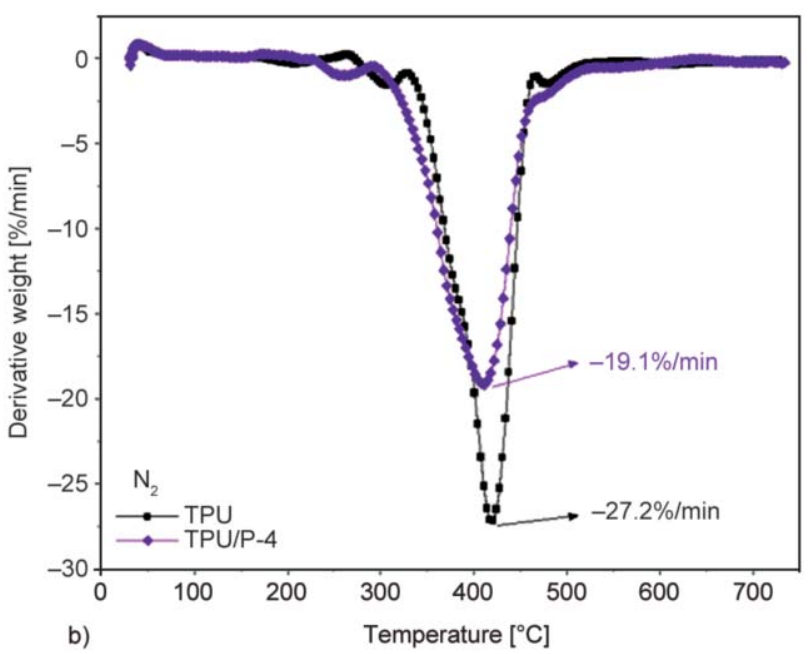

Figure 8. TGA (a) and dTG (b) under $\mathrm{N}_{2}$ atmosphere curves of TPU and its composites. 


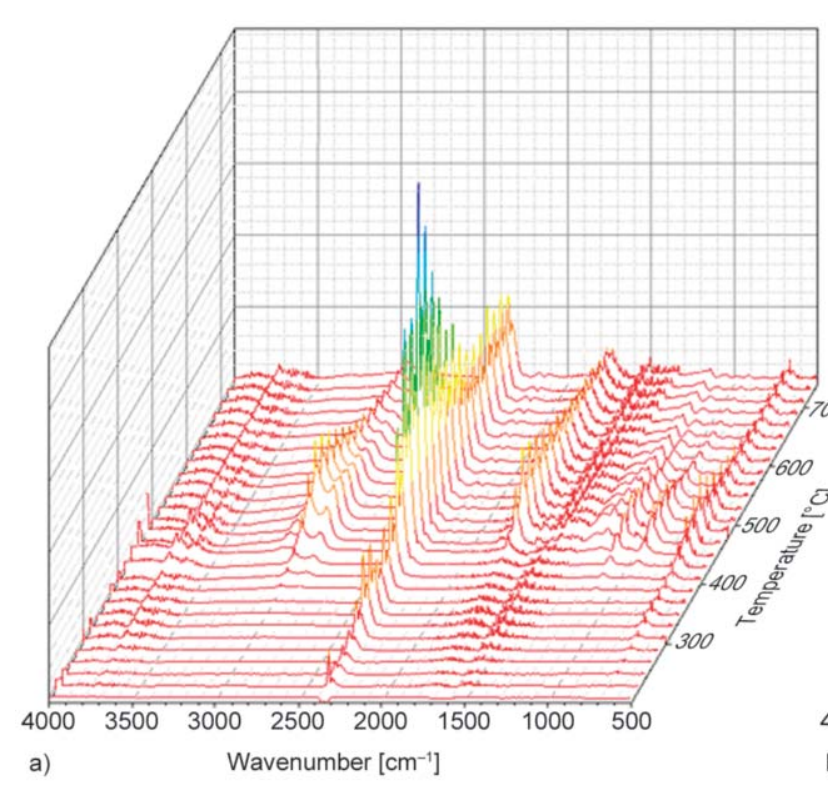

Figure 9. TG-IR spectra of TPU (a) and TPU/P-4 (b).

Table 3. The relevant combustion parameters from MCC.

\begin{tabular}{|l|c|c|}
\hline \multicolumn{1}{|c|}{ Sample } & $\begin{array}{c}\mathbf{p H R R} \\
{\left[\mathbf{W} \cdot \mathbf{g}^{-\mathbf{1}} \mathbf{]}\right.}\end{array}$ & $\begin{array}{c}\text { Temperature } \\
{\left[{ }^{\circ} \mathbf{C}\right]}\end{array}$ \\
\hline TPU & 527.9 & 414.4 \\
\hline TPU/P-1 & 460.2 & 415.2 \\
\hline TPU/P-2 & 368.2 & 411.1 \\
\hline TPU/P-3 & 324.5 & 389.3 \\
\hline TPU/P-4 & 333.6 & 382.7 \\
\hline
\end{tabular}

Then pure TPU and TPU/P-4 samples were further investigated using MCC test. This test excluded the physical factors and other external factors unrelated to combustion, and further analyzed the pyrolysis characteristics $[5,44]$. The related results were given in Table 3. The pHRR of pure TPU was $527.9 \mathrm{~W} / \mathrm{g}$, and the pHRR value of TPU/P-4 was $333.6 \mathrm{~W} / \mathrm{g}$, which was about $36.8 \%$ lower than that of TPU. From the temperature of reaching the peak value, TPU and TPU/P-4 samples reached the pHRR at 414.4 and $382.7^{\circ} \mathrm{C}$, respectively. TPU/P-4 reached its pHRR at a lower temperature, which was similar to the results of CCT and TG-IR test. Furthermore, there was a multi-peak phenomenon for the TPU/P-4 sample, which was attributed to the multiple fractures of the char residue layer. In other words, when PHM was heated in a three-dimensional environment, the char residue layer still had a good protective effect.

\subsection{Flame retardancy and toxicity reduction mechanism of PHM}

The flame-retardant and toxicity inhibition mechanism of PHM in TPU during the combustion process was inferred and shown in Figure 10. Under the

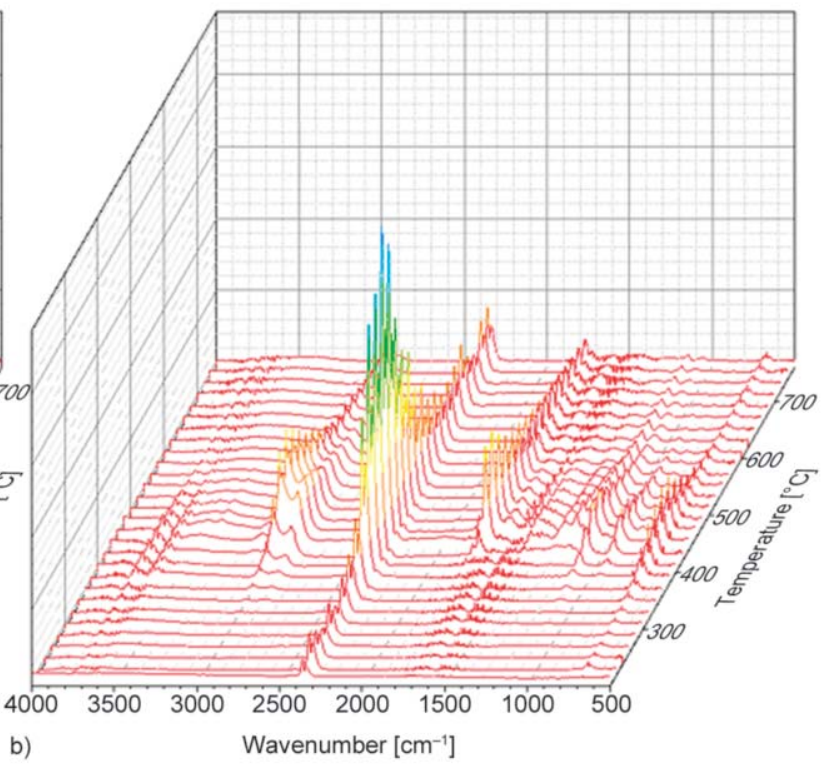

thermal radiation, the TPU composite was melted by heating. Because PHM is light, it can migrate quickly onto the surface of TPU composites to form PHM protective layer and accelerate the formation of char residue. However, before entering the environment, toxic and harmful gas released from TPU composites must pass through the PHM layer. At this time, PHM was closely arranged; these toxic gas could only be transferred along the PHM surface, forming a gas conduction path, which slowed down the release rate of toxic and harmful gas. Similarly, if the heat in the flame area wanted to transfer downward, it must pass through the PHM layer, too, forming the thermal conduction path. Due to the hollow structure of PHM, the thermal conductivity of PHM was low, and the thermal conduction was not complete, so the underlying material was protected. In short, the char residue layer of TPU/P-4 could effectively isolate the exchange of heat and decomposition products between the underlying materials and the environment and played a good role in protection.

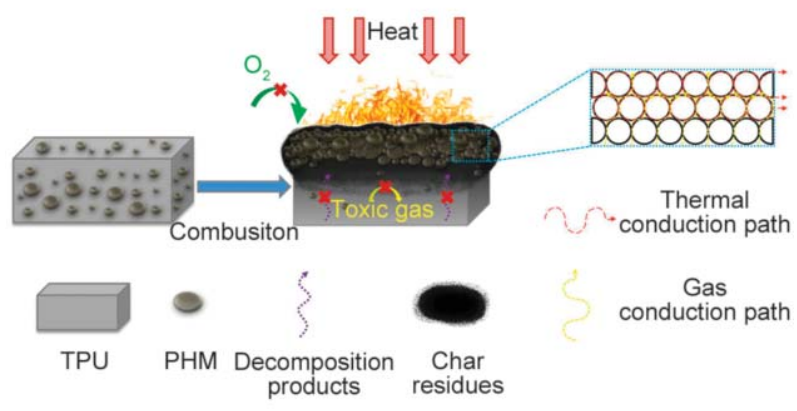

Figure 10. The flame retardant and toxicity inhibition mechanism of PHM. 


\section{Conclusions}

In this paper, PHM with a hollow closed-cell structure was synthesized. The results indicated clearly that PHM had good thermal stability and very good carbonization ability. PHM can be used as a flame retardant for TPU. PHM had obvious smoke suppression and flame retardant effect for TPU. In the combustion process, PHM can migrate onto the surface of the TPU composites and catalyze TPU carbonization to form a compact char residue layer with a high expansion degree and graphitization degree. The char residue layer could isolate the material and heat exchange between the underlying materials and the environment, which played a very good protective role, preventing the decomposition products from entering the flame zone in the combustion process and effectively inhibiting the release of toxic gas. Thus, the PHM improved flame retardancy, smoke, and poison suppression performance simultaneously.

\section{Acknowledgements}

The authors gratefully acknowledge the National Natural Science Foundation of China (No. 51776101), the Science and Technology Program of Guangzhou (201806010113), and the Project of the State Administration of Work Safety (Shandong-0039-2017AQ).

\section{References}

[1] Boubakri A., Haddar N., Elleuch K., Bienvenu Y.: Impact of aging conditions on mechanical properties of thermoplastic polyurethane. Materials and Design, 31, 4194-4201 (2010). https://doi.org/10.1016/j.matdes.2010.04.023

[2] Feng F., Ye L.: Morphologies and mechanical properties of polylactide/thermoplastic polyurethane elastomer blends. Journal of Applied Polymer Science, 119, 2778-2783 (2011). https://doi.org/10.1002/app.32863

[3] Mi H-Y., Li Z., Turng L-S., Sun Y., Gong S.: Silver nanowire/thermoplastic polyurethane elastomer nanocomposites: Thermal, mechanical, and dielectric properties. Materials and Design (1980-2015), 56, 398-404 (2014). https://doi.org/10.1016/j.matdes.2013.11.029

[4] Chen X., Feng X., Jiao C.: Combustion and thermal degradation properties of flame-retardant TPU based on EMImPF $_{6}$. Journal of Thermal Analysis and Calorimetry, 129, 851-857 (2017).

https://doi.org/10.1007/s10973-017-6189-4
[5] Chen X., Wang W., Li S., Jiao C.: Fire safety improvement of para-aramid fiber in thermoplastic polyurethane elastomer. Journal of Hazardous Materials, 324, 789-796 (2017).

https://doi.org/10.1016/j.jhazmat.2016.11.065

[6] Jiao C., Jiang H., Chen X.: Properties of fire agent integrated with molecular sieve and tetrafluoroborate ionic liquid in thermoplastic polyurethane elastomer. Polymers for Advanced Technologies, 30, 2159-2167 (2019).

https://doi.org/10.1002/pat.4622

[7] Jiao C., Wang H., Chen X., Tang G.: Flame retardant and thermal degradation properties of flame retardant thermoplastic polyurethane based on HGM@ [EOOEMIm] $\left[\mathrm{BF}_{4}\right]$. Journal of Thermal Analysis and Calorimetry, 135, 3141-3152 (2018).

https://doi.org/10.1007/s10973-018-7505-3

[8] Shan X., Zhang P., Song L., Hu Y., Lo S.: Compound of nickel phosphate with $\mathrm{Ni}(\mathrm{OH})\left(\mathrm{PO}_{4}\right)^{2-}$ layers and synergistic application with intumescent flame retardants in thermoplastic polyurethane elastomer. Industrial and Engineering Chemistry Research, 50, 7201-7209 (2011). https://doi.org/10.1021/ie2001555

[9] Li H., Ning N., Zhang L., Wang Y., Liang W., Tian M.: Different flame retardancy effects and mechanisms of aluminium phosphinate in PPO, TPU and PP. Polymer Degradation and Stability, 105, 86-95 (2014). https://doi.org/10.1016/j.polymdegradstab.2014.03.032

[10] Chen X., Ma C., Jiao C.: Enhancement of flame-retardant performance of thermoplastic polyurethane with the incorporation of aluminum hypophosphite and irongraphene. Polymer Degradation and Stability, 129, 275285 (2016).

https://doi.org/10.1016/j.polymdegradstab.2016.04.017

[11] Lin M., Li B., Li Q., Li S., Zhang S.: Synergistic effect of metal oxides on the flame retardancy and thermal degradation of novel intumescent flame-retardant thermoplastic polyurethanes. Journal of Applied Polymer Science, 121, 1951-1960 (2011).

https://doi.org/10.1002/app.33759

[12] Dike A. S., Tayfun U., Dogan M.: Influence of zinc borate on flame retardant and thermal properties of polyurethane elastomer composites containing huntite-hydromagnesite mineral. Fire and Materials, 41, 890-897 (2017).

https://doi.org/10.1002/fam.2428

[13] Kajiwara N., Noma Y., Takigami H.: Brominated and organophosphate flame retardants in selected consumer products on the japanese market in 2008. Journal of Hazardous Materials, 192, 1250-1259 (2011). https://doi.org/10.1016/j.jhazmat.2011.06.043

[14] Hooshangi Z., Feghhi S. A. H., Sheikh N.: The effect of electron-beam irradiation and halogen-free flame retardants on properties of poly butylene terephthalate. Radiation Physics and Chemistry, 108, 54-59 (2015). https://doi.org/10.1016/j.radphyschem.2014.11.012 
[15] Ravichandran S., Bouldin R. M., Kumar J., Nagarajan R.: A renewable waste material for the synthesis of a novel non-halogenated flame retardant polymer. Journal of Cleaner Production, 19, 454-458 (2011).

https://doi.org/10.1016/j.jclepro.2010.09.010

[16] Tamura K., Ohyama S., Umeyama K., Kitazawa T., Yamagishi A.: Preparation and properties of halogenfree flame-retardant layered silicate-polyamide 66 nanocomposites. Applied Clay Science, 126, 107-112 (2016). https://doi.org/10.1016/j.clay.2016.02.027

[17] An K., Hyeon T.: Synthesis and biomedical applications of hollow nanostructures. Nano Today, 4, 359-373 (2009).

https://doi.org/10.1016/j.nantod.2009.06.013

[18] Zhang Q., Wang W., Goebl J., Yin Y.: Self-templated synthesis of hollow nanostructures. Nano Today, 4, 494 507 (2009). https://doi.org/10.1016/j.nantod.2009.10.008

[19] Li N., Zhu X., Zhang C., Lai L., Jiang R., Zhu J.: Controllable synthesis of different microstructured $\mathrm{MnO}_{2}$ by a facile hydrothermal method for supercapacitors. Journal of Alloys and Compounds, 692, 26-33 (2017). https://doi.org/10.1016/j.jallcom.2016.08.321

[20] Li S., Li A., Zhang R., He Y., Zhai Y., Xu L.: Hierarchical porous metal ferrite ball-in-ball hollow spheres: General synthesis, formation mechanism, and high performance as anode materials for Li-ion batteries. Nano Research, 7, 1116-1127 (2014). https://doi.org/10.1007/s12274-014-0474-3

[21] Wang S., Zhang X., Li S., Fang Y., Pan L., Zou J-J.: C-doped $\mathrm{ZnO}$ ball-in-ball hollow microspheres for efficient photocatalytic and photoelectrochemical applications. Journal of Hazardous Materials, 331, 235-245 (2017). https://doi.org/10.1016/j.jhazmat.2017.02.049

[22] Xing X., Ma Y., Li J., Fan G., Ding H., Ma X., Yang L., Xi G.: Facile one-pot synthesis and photocatalytic properties of hierarchically structural $\mathrm{BiVO}_{4}$ with different morphologies. CrystEngComm, 16, 10218-10226 (2014). https://doi.org/10.1039/c4ce01198h

[23] Jiao C., Wang H., Li S., Chen X.: Fire hazard reduction of hollow glass microspheres in thermoplastic polyurethane composites. Journal of Hazardous Materials, 332, 176-184 (2017). https://doi.org/10.1016/j.jhazmat.2017.02.019

[24] Jiao C., Wang H., Chen X.: An efficient flame-retardant and smoke-suppressant agent by coated hollow glass microspheres with ammonium molybdophosphate for thermoplastic polyurethane. Journal of Thermal Analysis and Calorimetry, 137, 1579-1589 (2019). https://doi.org/10.1007/s10973-019-08044-8

[25] Wang H., Jiao C., Zhao L., Chen X.: Preparation and characterization of $\mathrm{TiO}_{2}$-coated hollow glass microsphere and its flame-retardant property in thermoplastic polyurethane. Journal of Thermal Analysis and Calorimetry, 131, 2729-2740 (2017).

https://doi.org/10.1007/s10973-017-6719-0
[26] Wang D., Wang J., Hu Y.: Low-cost synthesis of hollow mesoporous silica spheres and its application in the removal of aromatic volatiles. Materials Letters, 208, 5053 (2017). https://doi.org/10.1016/j.matlet.2017.05.016

[27] Qiu S., Ma C., Wang X., Zhou X., Feng X., Yuen R. K. $\mathrm{K}$., $\mathrm{Hu}$ Y.: Melamine-containing polyphosphazene wrapped ammonium polyphosphate: A novel multifunctional organic-inorganic hybrid flame retardant. Journal of Hazardous Materials, 344, 839-848 (2018). https://doi.org/10.1016/j.jhazmat.2017.11.018

[28] Yang H., Jiang Y., Liu H., Xie D., Wan C., Pan H., Jiang S.: Mechanical, thermal and fire performance of an inorganic-organic insulation material composed of hollow glass microspheres and phenolic resin. Journal of Colloid and Interface Science, 530, 163-170 (2018). https://doi.org/10.1016/j.jcis.2018.06.075

[29] Hu X-M., Zhao Y-Y., Cheng W-M.: Effect of formaldehyde/phenol ratio $(\mathrm{F} / \mathrm{P})$ on the properties of phenolic resins and foams synthesized at room temperature. Polymer Composites, 36, 1531-1540 (2015). https://doi.org/10.1002/pc. 23060

[30] Asaro L., Manfredi L. B., Pellice S., Procaccini R., Rodriguez E. S.: Innovative ablative fire resistant composites based on phenolic resins modified with mesoporous silica particles. Polymer Degradation and Stability, 144, 7-16 (2017).

https://doi.org/10.1016/j.polymdegradstab.2017.07.023

[31] Cardona F., Kin-Tak A. L., Fedrigo J.: Novel phenolic resins with improved mechanical and toughness properties. Journal of Applied Polymer Science, 123, 21312139 (2012). https://doi.org/10.1002/app.34719

[32] Rallini M., Wu H., Natali M., Koo J., Torre L.: Nanostructured phenolic matrices: Effect of different nanofillers on the thermal degradation properties and reaction to fire of a resol. Fire and Materials, 41, 817-825 (2017). https://doi.org/10.1002/fam.2425

[33] Liu Y., Jing X.: Miscibility, morphology, and thermal properties of hyperbranched polyborates modified phenolic resins. Journal of Polymer Science Part B: Polymer Physics, 46, 2012-2021 (2008).

https://doi.org/10.1002/polb.21530

[34] Liu X., Li H., Ma T., Li K.: Preparation of phenolic hollow microspheres via in situ polymerization. Polymer International, 58, 465-468 (2009).

https://doi.org/10.1002/pi.2567

[35] Guo Z., Wang C., Li J.: An intumescent-like flame-retardant effect of hollow carbon precursor on acrylonitrile-butadiene-styrene/oligomeric aryl phosphate/novolac epoxy composites. Polymer-Plastics Technology and Engineering, 55, 1441-1449 (2016). https://doi.org/10.1080/03602559.2016.1163605 
[36] Chen W-C., Liu Y-T., Kuo S-W.: Highly thermal stable phenolic resin based on double-decker-shaped poss nanocomposites for supercapacitors. Polymers, 12, 2151/1-2151/15 (2020).

https://doi.org/10.3390/polym12092151

[37] Bertrand G., Bertrand P., Roy P., Rio C., Mevrel R.: Low conductivity plasma sprayed thermal barrier coating using hollow psz spheres: Correlation between thermophysical properties and microstructure. Surface and Coatings Technology, 202, 1994-2001 (2008). https://doi.org/10.1016/j.surfcoat.2007.08.042

[38] Shao J-J., Lv W., Yang Q-H.: Self-assembly of graphene oxide at interfaces. Advanced Materials, 26, 5586-5612 (2014). https://doi.org/10.1002/adma.201400267

[39] Xu B., Feng T., Agne M. T., Zhou L., Ruan X., Snyder G. J., Wu Y.: Highly porous thermoelectric nanocomposites with low thermal conductivity and high figure of merit from large-scale solution-synthesized $\mathrm{Bi}_{2} \mathrm{Te}_{2.5} \mathrm{Se}_{0.5}$ hollow nanostructures. Angewandte Chemie International Edition, 56, 3546-3551 (2017).

https://doi.org/10.1002/anie.201612041

[40] Dasari A., Yu Z-Z., Cai G-P., Mai Y-W.: Recent developments in the fire retardancy of polymeric materials. Progress in Polymer Science, 38, 1357-1387 (2013). https://doi.org/10.1016/j.progpolymsci.2013.06.006

[41] Hapuarachchi T. D., Peijs T.: Multiwalled carbon nanotubes and sepiolite nanoclays as flame retardants for polylactide and its natural fibre reinforced composites. Composites Part A: Applied Science and Manufacturing, 41, 954-963 (2010).

https://doi.org/10.1016/j.compositesa.2010.03.004

[42] Li Y., Li B., Dai J., Jia H., Gao S.: Synergistic effects of lanthanum oxide on a novel intumescent flame retardant polypropylene system. Polymer Degradation and Stability, 93, 9-16 (2008).

https://doi.org/10.1016/j.polymdegradstab.2007.11.002

[43] Chen X., Wang W., Jiao C.: Para-aramid fiber modified by melamine polyphosphate and its flame retardancy on thermoplastic polyurethane elastomer. RSC Advances, 7, 53172-53180 (2017).

https://doi.org/10.1039/c7ra10282h

[44] Chen X., Zhang X., Wang W., Wang Y., Jiao C.: Firesafe agent integrated with oyster shell and melamine polyphosphate for thermoplastic polyurethane. Polymers for Advanced Technologies, 30, 1576-1588 (2019). https://doi.org/10.1002/pat.4588

[45] Tabuani D., Bellucci F., Terenzi A., Camino G.: Flame retarded thermoplastic polyurethane (TPU) for cable jacketing application. Polymer Degradation and Stability, 97, 2594-2601 (2012).

https://doi.org/10.1016/j.polymdegradstab.2012.07.011
[46] Ricciardi M., Antonucci V., Zarrelli M., Giordano M.: Fire behavior and smoke emission of phosphate-based inorganic fire-retarded polyester resin. Fire and Materials, 36, 203-215 (2012).

https://doi.org/10.1002/fam.1101

[47] Liu L., Chen X., Jiao C.: Influence of ferrocene on smoke suppression properties and combustion behavior of intumescent flame-retardant epoxy composites. Journal of Thermal Analysis and Calorimetry, 122, 437-447 (2015). https://doi.org/10.1007/s10973-015-4928-y

[48] Wilke A., Langfeld K., Ulmer B., Andrievici V., Hörold A., Limbach P., Bastian M., Schartel B.: Halogen-free multicomponent flame retardant thermoplastic styreneethylene-butylene-styrene elastomers based on ammonium polyphosphate-expandable graphite synergy. Industrial and Engineering Chemistry Research, 56, 82518263 (2017).

https://doi.org/10.1021/acs.iecr.7b01177

[49] Chen X., Wang W., Jiao C.: A recycled environmental friendly flame retardant by modifying para-aramid fiber with phosphorus acid for thermoplastic polyurethane elastomer. Journal of Hazardous Materials, 331, 257-264 (2017).

https://doi.org/10.1016/j.jhazmat.2017.02.011

[50] Wang J., Ma C., Mu X., Cai W., Liu L., Zhou X., Hu W., Hu Y.: Construction of multifunctional $\mathrm{MoSe}_{2}$ hybrid towards the simultaneous improvements in fire safety and mechanical property of polymer. Journal of Hazardous Materials, 352, 36-46 (2018).

https://doi.org/10.1016/j.jhazmat.2018.03.003

[51] Wang S., Gao R., Zhou K.: The influence of cerium dioxide functionalized reduced graphene oxide on reducing fire hazards of thermoplastic polyurethane nanocomposites. Journal of Colloid and Interface Science, 536, 127-134 (2019). https://doi.org/10.1016/j.jcis.2018.10.052

[52] Qian L., Ye L., Qiu Y., Qu S.: Thermal degradation behavior of the compound containing phosphaphenanthrene and phosphazene groups and its flame retardant mechanism on epoxy resin. Polymer, 52, 5486-5493 (2011). https://doi.org/10.1016/j.polymer.2011.09.053

[53] Jiao C., Jiang H., Chen X.: Reutilization of abandoned molecular sieve as flame retardant and smoke suppressant for thermoplastic polyurethane elastomer. Journal of Thermal Analysis and Calorimetry, 138, 3905-3913 (2019). https://doi.org/10.1007/s10973-019-08328-Z 